\title{
Critical Thinking Enhancement of Nursing Student
}

\author{
Awais Jamil ${ }^{1 *}$, Muhammad Hayat ${ }^{2}$, Jagdesh $\mathrm{Kumar}^{3}$
}

${ }^{1}$ Nurse Instructor

${ }^{2}$ Assistant Professor

${ }^{3}$ Head Nurse

\begin{tabular}{l}
\hline DOI: $10.36348 /$ sjnhc.2019.v02i12.011 \\
*Corresponding author: Awais Jamil
\end{tabular}

Background: Critical thinking is a key element in the field of education. Where many studies have been published regarding the importance of critical thinking while practicing or studying nursing in hospital settings or academic environment, this project indicates the development of critical thinking in nursing students at all levels of their nursing program. Objective: The purpose of the study is to enhance critical thinking in the nursing students to improve clinical practice and judgment. Methodology: A sample of 20 nursing students participated. A questionnaire tool regarding Knowledge, Attitude and Practice of nursing student to enhance critical thinking was used for pre and post-test evaluation. In implementation phase, participants presented with different critical thinking skill development presentations which were based on clinical scenarios. Results: The result analyzed was 18 out 20 participants strongly agreed that critical thinking development workshop enhanced the skill in patient care. The critical thinking assessment too was further assessed over the time period for their consistency and sustainability on utilizing the critical thinking strategy. Conclusion: The enhancement in critical thinking in nursing students is a necessary development in one's ability ultimately improving patient care outcomes and quality indicators.

Keywords: Nursing Student, critical thinking, clinical practice and judgment.

Copyright @ 2019: This is an open-access article distributed under the terms of the Creative Commons Attribution license which permits unrestricted use, distribution, and reproduction in any medium for non-commercial use (NonCommercial, or CC-BY-NC) provided the original author and source are credited.

\section{BACKGROUND}

Medical discipline has dramatically changed day by day with prompt changing in practice, technology and economic milieu that result in noncompliance of medical services among patients and families [1]. Nurses have to work hard to be updated and smart to understand, practice and implicate advanced lifesaving technology and intricate care through critical thinking [2-5].

Critical thinking is considered a basic mental process for knowledge acquisition, its development and it implication in the field of education, sociology, medical, ethical, management and politics for problem solving and decision making [6]. Critical thinking results in change in role of nurses' perspective to caring, helping in recovery, reducing multiple acute care readmission and disease progression [2].

The study of Wager 2014 highlighted that the deficiencies among nursing education with substantive deficiency was implementation of critical thinking in nursing practice [4]. Primarily, novice or beginning nurse is deficient of critical thinking skill while providing effective nursing care [7]. They are expected to scrutinize acute health problems and intercede immediately [7-9]. The consequently lead to poor prognosis and health outcomes of patient including minor injury to death [7]. The aim of the study is to enhance critical thinking in the nursing students to improve clinical practice and judgment.

\section{LITERATURE REVIEW}

The literature review compassed on the revival in the health care settings that emphasized the significance of critical thinking skills which should be part of the fundamental nurses' educational program. The consequence of this is the majority of undergraduate nursing programs made critical thinking as part of their educational outcomes [10].

The significant demand for implementing teaching and measuring critical thinking is that there is no absolute definition of critical thinking. This encompassed that there is no single way to assess or teach critical thinking to nursing student. But active searching of literature review helped to find the way to infuse the habit of critical thinking (self - confidence, 
inquiry, analytical abilities, reasoning, and open mindedness) in nursing students [11].

Active learning had fundamental requirement for students [12]. The evidence showed that active learning among students influenced by both cognitive and non-cognitive factors [13]. These factor influenced by the classroom milieu. The physical environment (classroom size, lightening, noise level, seating arrangement, temperature, and distance between faculties to student) affected the process either directly or indirectly to student active learning [14].

Didactic teaching and rote learning style is most commonly used in Pakistan but very limited researches done here. Students encouraged to listen to lessons, made their notes and then comply with books for professional examinations [15]. 1998 National survey reported that nursing students reflected comments were, "I am told", "No need to understand, just remember" [16]. Above all researches concluded that critical thinking need to be in-parted to nursing student for developing milieu of safe practice and holistic care.

\section{METHODS}

\section{Study Design}

Using an descriptive cross - sectional study design with a pre and posttest approach, the entire study consists of three phases; assessment, intervention and post assessment.

\section{Population and Sample}

The study population comprises the entire nursing student in nursing schools/colleges in Pakistan. For this proposed study convenient sampling used and total 20 nursing students enrolled in nursing BSN program.

\section{Data Collection}

The data collected with help of structured questionnaire for knowledge and attitude for about 3060 mints. Demographic information of each participant student was obtained from them.

\section{Data Analysis}

The recorded data were analyzed with statistical package of social sciences (SPSS) to conduct analysis through descriptive statistics.

\section{RESULTS \\ Participants' Demographics}

Data collected from the private and public institutions 20 subjects participated in the study. Among them $66 \%$ were female and $33 \%$ male. Majority of them $(77 \%)$ are in final year and rest of them (33\%) from third and second year of BSc nursing program. The participant age ranging from 20 to 25 year with majority of $53.9 \%$ ranging from 20 to 22 years.

\section{Significance of Critical Thinking}

The structured questionnaire filled with both pre and post - test phase. During their pre - test $83 \%$ subjects strongly agree that importance of critical thinking tool in nursing profession.

Also stating $56 \%$ suggested that critical thinking promoted while exploring multiple aspects of a case study but post - test result significantly improved to $83 \%$. Similarly $56 \%$ also in the favor that problem based learning enhanced their critical thinking process which enhanced to $67 \%$ in post - test phase. It has been seen that $61 \%$ of subjects felt that their clinical practice become improved as they used to implement their skills of critical thinking which in turns upgraded to $67 \%$.

Nursing curriculum deficient to develop and provide opportunities for critical thinking skill. 39\% of participants were in the favor of activities for enhancing critical thinking by including such subjects in nursing curriculum. Whereas $78 \%$ of participant supported that reasoning and discussion build critical thinking skill in them. Also $83 \%$ were in felt that critical thinking ability to lead to better nursing educational outcomes in post test phase.

Critical thinking in nursing profession can improve standard of nursing care practice with $78 \%$ during pre - test while become $67 \%$ during post - test phase. Active learning has positive association with critical thinking with $67 \%$ of participant favors. Also written and oral assignment developed critical thinking skills in $67 \%$ of participants.

\section{DISCUSSION}

The findings of the assessment phase of study reveals that majority of nursing students' lack of critical thinking skills as part of their curriculum and clinical practice. This concluded that significance of critical thinking in clinical practice. Following studies supported that the significance of critical thinking in nursing which directly influenced by that classroom physical environment, teaching methods, teacher knowledge and critical thinking skills, social skills and teaching experiences $[17,18]$. Some studies stated that problem based learning more effective to develop critical thinking skill. With help of problem solve method student were able to develop critical thinking skill.

In conclusion to all this critical thinking is poorly studied in nursing discipline. Yet to some extent it reveals that there is need to enhanced teachers education with respect of critical thinking skills, teaching methodology, curriculum revision, critical thinking case studies and evaluation tools.

\section{RECOMMENDATIONS}

- To achieve the effective and safe clinical practice nursing educator must exhibit critical thinking 
skills in themselves.

- Case studies and clinical scenarios based on critical thinking enhancement skills must become the part of nursing education curriculum.

- Instead of viva and oral examination, critical thinking objective structured clinical examination (OSCE) must use as tool for both formative and summative assessments.

\section{REFERENCES}

1. Giddens, J. F., \& Brady, D. P. (2007). Rescuing nursing education from content saturation: The case for a concept-based curriculum. Journal of Nursing Education, 46(2).

2. Institute of Medicine (US). Committee on the Robert Wood Johnson Foundation Initiative on the Future of Nursing. (2011). The future of nursing: Leading change, advancing health. Washington, DC: National Academies Press.

3. Hughes, R. (Ed.). (2008). Patient safety and quality: An evidence-based handbook for nurses (Vol. 3). Rockville, MD: Agency for Healthcare Research and Quality.

4. Wagner, E. A. (2014). Using a kinesthetic learning strategy to engage nursing student thinking, enhance retention, and improve critical thinking. Journal of Nursing Education, 53(6), 348-351.

5. Newton, S. E., \& Moore, G. (2013). Critical thinking skills of basic baccalaureate and accelerated second-degree nursing students. Nursing Education Perspectives, 34(3), 154-158.

6. Simpson, E., \& Courtney, M. D. (2002). Critical thinking in nursing education: Literature review. International journal of nursing practice, 8(April), 89-98.

7. Wilgis, M., \& McConnell, J. (2008). Concept mapping: An educational strategy to improve graduate nurses' critical thinking skills during a hospital orientation program. The journal of continuing education in Nursing, 39(3), 119-126.

8. Wilkinson, J. M. (1996). Nursing process: A critical thinking approach (Vol. 2). AddisonWesley Nursing.
9. Rosseter, R. J. (2014). The impact of education on nursing practice. American Association of Colleges of Nursing Fact Sheet.

10. Profetto-McGrath, J., Smith, K. B., Day, R. A., \& Yonge, O. (2004). The questioning skills of tutors and students in a context based baccalaureate nursing program. Nurse education today, 24(5), 363-372.

11. Angel, B. F., Duffey, M., \& Belyea, M. (2000). An evidence-based project for evaluating strategies to improve knowledge acquisition and criticalthinking performance in nursing students. Journal of Nursing Education, 39(5), 219-228.

12. Van Amburgh, J. A., Devlin, J. W., Kirwin, J. L., \& Qualters, D. M. (2007). A tool for measuring active learning in the classroom. American journal of pharmaceutical education, 71(5), 85.

13. Gloria, A. M., Castellanos, J., \& Orozco, V. (2005). Perceived educational barriers, cultural fit, coping responses, and psychological well-being of Latina undergraduates. Hispanic Journal of Behavioral Sciences, 27(2), 161-183.

14. Fitz Patrick, S., Wenyi, H., \& Younghoon, K. (2000, February). Meaningful learning through mindful activities: Designing constructivist learning environments for the social welfare support. In annual conference of the Association for Educational Communications and Technology, Long Beach, CA. Retrieved from http://www. personal. psu. edu/users/w/x/wxh139/propose1. htm.

15. Davies, L., \& Iqbal, Z. (1997). Tensions in Teacher Training for School Effectiveness: The Case of Pakistan*.

16. Kamal, I. (1999). Report on the evaluation of implementation of the revised Nursing Curriculum in Pakistan. Karachi: Rahnum.

17. Twibell, R., Ryan, M., \& Hermiz, M. (2005). Faculty perceptions of critical thinking in student clinical experiences. Journal of Nursing Education, 44(2), 71-80.

18. Schaber, P., \& Shanedling, J. (2012). Online course design for teaching critical thinking. Journal of allied health, 41(1), 9E-14E. 